Research Paper:

\title{
Effect of Family-Centered Empowerment Model on the Care Burden of the Caregivers of Older Adults with Heart Failure
}

\author{
Sedighe Jafari-Diziche ${ }^{1}$ (D), Fateme-Sadat Izadi-Avanji' ${ }^{\text {(D) }}$, Fateme Atoof ${ }^{2}$ (D), Seyed-Majid Derakhshandeh ${ }^{3}$ (D), Ismail Azizi-Fini ${ }^{*}$ (iD)
}

1. Trauma Nursing Research Center, Faculty of Nursing and Midwifery, Kashan University of Medical Sciences, Kashan, Iran.

2. Department of Biostatistic, Faculty of Health, Kashan University of Medical Sciences, Kashan, Iran.

3. Isfahan Cardiovascular Research Insititute, Isfahan University of Medical Sciences, Isfahan, Iran

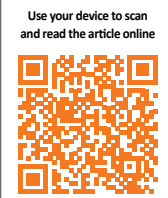

ditat On: Jafari-Diziche, A., et al. 2021. Effect of Family-Centered Empowerment Model on the Care Burden of the Caregivers of Older Adults with Heart Failure. Journal of Client-Centered Nursing Care, 7(4), pp. 275-284. https://doi.org/10.32598/ JCCNC.7.4.305.3

https://doi.org/10.32598/JCCNC.7.4.305.3

Article info:

Received: 10 May 2021

Accepted: 13 Sep 2021

Published: 01 Nov 2021

Keywords:

Elderly, Heart failure, Empowerment, Family caregiver, Care burden

\section{A B S T RA C T}

Background: Developing a chronic disease, like heart failure in older adults disrupts the foundations of the family and imposes a heavy burden on family members. The aim of this study was to determine the effect of the Family-Centered Empowerment Model (FCEM) on the care burden of family caregivers of older adults with heart failure.

Methods: It was a quasi-experimental study with a controlled before and after design, which was conducted on 80 primary caregivers of older adults with heart failure referring to health centers affiliated with Kashan University of Medical Sciences, Kashan, Iran. The subjects were nonrandomly assigned to either the control $(n=40)$ or intervention $(n=40)$ groups. The program was implemented based on the concepts of the model (perceived threat, self-efficacy, self-esteem, and evaluation) in eight 2-hour sessions, twice a week for four consecutive weeks. Both groups answered the Zarit Burden Interview (ZBI) in the beginning, in the end, and one month after the study. The data were analyzed by Chi-square, t-test, and the repeated measures ANOVA using SPSS 16 software.

Results: There was no significant difference between the two groups regarding the pretest mean score of care burden $(\mathrm{P}>0.05)$. However, the groups' mean score of care burden was significantly different immediately after the intervention $(\mathrm{P}<0.05)$ and one month after the study $(\mathrm{P}<0.05)$. The repeated measures ANOVA illustrated a significant difference between the mean scores of care burden in the three measurement time points $(\mathrm{P}<0.0001)$.

Conclusion: Implementation of the FCEM model reduces the burden of care in caregivers of older adults with heart failure. It is suggested that this model be used in training programs for older adults with heart failure and their caregivers.

\section{"Corresponding Author:}

Ismail Azizi-Fini, PhD.

Address: Trauma Nursing Research Center, Faculty of Nursing and Midwifery, Kashan University of Medical Sciences, Kashan, Iran

Tel: +98 (912) 2475747

E-mail:azizifinies@yahoo.com 


\section{Highlights}

- Heart failure is one of the most common cardiovascular disorders worldwide.

- Caregiver burden is the physical, psychological, and social responses of the caregiver to the imbalance between caring needs and their other tasks.

- The family-centered empowerment model reduces the caregiver burden in caregivers of older adults with heart failure.

\section{Plain Language Summary}

Heart failure is the inability of the heart to pump enough blood to meet the tissues' need for oxygen and nutrients, which could lead to shortness of breath, swelling of the ankles and legs, cognitive impairment, fatigue, lethargy, and weight gain due to fluid retention. Neglecting the training of patients with heart failure and their family caregivers is the most important defect in the process of treatment and caring for these patients, which makes the patients more likely to be readmitted to the hospital. Family caregivers experience many problems in response to the imbalance between meeting the caring needs of their patients and other tasks of themselves. The results of this study revealed that the family-centered empowerment model reduces the caregiver burden in family caregivers of older adults with heart failure.

\section{Introduction}

eart Failure (HF) is one of the most com$\mathrm{H}$ mon cardiovascular disorders worldwide. $\mathrm{HF}$, often defined as congestive HF, is the inability of the heart to pump enough blood to meet the tissues' need for oxygen and nutrients (Casimir et al. 2013). Approximately $1 \%$ of the population over the age of 50 and $10 \%$ of older adults over the age of 80 suffer from HF (Salehi, Mehralin \& Hasheminia 2016). The 5-year mortality of HF has been reported as $45 \%$ in women and $60 \%$ in men (Chong, Ding \& Heng 2011). Shortness of breath, especially when lying down, swelling of the ankles and legs, cognitive impairment, fatigue, lethargy, and weight gain due to fluid retention are the most prevalent symptoms of HF (Chong, Ding \& Heng 2011; Kato et al. 2009).

According to the New York Heart Association, HF has four classes in terms of its impact on daily activities. In class one (mild), there are no restrictions on physical activity. In class two (mild), there are slight restrictions in physical activity, in class three (intermediate) there are significant limitations in physical activity, and in class 4, doing any physical activity is accompanied by a feeling of discomfort (Nomali et al. 2017).

The incidence of HF in older adults is worrying and anxious for patients and their families (Rezai et al. 2017). The occurrence of chronic diseases in older adults disrupts the foundations of the family and imposes a heavy burden on family members (Kato et al. 2009).
Neglecting the education of patients with HF and their family caregivers is the most important defect in the process of treatment and caring for these patients, which makes the patients more likely to be readmitted to the hospital (Rezai et al. 2017; Utne et al. 2013) and increases the caregiver burden in their families.

Caregiver burden is the physical, psychological, and social responses of the caregiver to the imbalance between the caring needs of the patient and other tasks of the caregiver. This imbalance affects the caregivers' personal, social, physical, emotional, and financial status (Milbury et al. 2013). In this regard, caring for the elderly with HF creates many problems and pressures for the family caregivers of these patients (Dharmarajan et al. 2013).

High pressure on patients' caregivers may lead to family isolation, deprivation of social support, disruption of family relationships, inadequate patient care, and abandonment of the patient. Although poor self-care can exacerbate the disease, the quality of support and care provided by the family can also affect the quality of life of patients and their families (Milbury et al. 2013; Utne et al. 2013).

It has been reported that family caregivers of patients with type 2 diabetes experience a moderate burden (Bamari, Madarshahian \& Barzgar 2016). Also, the family caregivers of patients with cancer have experienced a moderate burden (Mollaei et al. 2019). In another study, the family caregivers' burden of patients with breast cancer was reported as high (Vahidi et al. 2016). The patient's family is a key element in his/her recovery and 
health (Rahimi Kordshooli, Rakhshan \& Ghanbari 2018). Therefore, the empowerment of patients and their families has been considered in recent years. Promoting family members' caring knowledge and involving them in patient care help them gain a better understanding of the patient's condition, resolve patient problems more effectively, and better manage their physical and mental stress.

The Family-Centered Empowerment Model (FCEM) emphasizes individual effectiveness and the role of other family members in three dimensions of motivational, psychological (self-esteem and self-control), and problematic individual characteristics (knowledge, attitudes, and perceived threat) (Heidari et al. 2007). Family empowerment has three main characteristics, including the ability to review the required educational resources, the ability to make decisions and solve problems, and the ability to communicate to meet existing needs (Sanaie et al. 2014). The FCEM includes four major steps: (1) perception of threat, (2) self-efficacy, (3) self-esteem, and (4) evaluation. Therefore, in order to achieve the best result, it is expected that the FCEM can simultaneously increase knowledge, skills, values, and beliefs of self-confidence and self-control in the patients and their families (Moattari et al. 2012).

The FCEM helps plan, implement, and evaluate health care through reciprocal partnerships of caregivers, patients, and families (Bamari, Madarshahian \& Barzgar 2016). Studies have shown that continuous training and empowerment of primary caregivers can significantly reduce patient readmission and mortality (Bamari, Madarshahian \& Barzgar 2016; Mollaei et al. 2019).

The effects of the FCEM have been studied in various diseases. The application of FCEM could improve the lifestyle of patients with HF (Rahimi Kordshooli, Rakhshan \& Ghanbari 2018). The effects of FCEM on reducing the care burden of caregivers of children with epilepsy (Shoghi, Shahbazi \& Seyedfatemi 2019) and reducing the perceived threats in patients with HF (Rahimi Kordshooli, Rakhshan \& Ghanbari 2018) has also been confirmed. However, the effect of using this model on the care burden of family caregivers of older adults with $\mathrm{HF}$ has not received much attention.

Accordingly, this study was carried out to determine the effect of using FCEM on the care burden in caregivers of older adults with HF.

\section{Materials and Methods}

\section{Design, setting, and sample}

This research was a quasi-experimental study with a controlled before and after design, which was conducted in 2019 on 80 primary caregivers of older adults with HF. Their patients were previously admitted to health centers affiliated with the Kashan University of Medical Sciences, Kashan, Iran.

Criteria for inclusion of caregivers were being primarily responsible for caring for the elderly with $\mathrm{HF}$ as a family member, caring for the patient for at least 6 months, and being literate. The patients were elderly people over 60 years with a definite diagnosis of HF and the absence of other major diseases, such as malignancies. Patient death, hospitalization during the study, change of the caregiver during the study, and being absent for more than two sessions were considered exclusion criteria.

The patients were found by reviewing the records available in the heart failure clinics of the health centers. They were then contacted via the available telephone number and their primary caregivers were invited to participate in the study. If the subject agreed to participate in the study, a meeting was held with the presence of groups of six caregivers and the objectives of the research were explained to them.

The sample size was estimated based on the findings of a former study (Mollaei et al. 2019) and the formula for comparing two means. Then, considering the type I error of 0.05 , type II error of $0.20, \mu 1$ of 55.37 , and $\mu 2$ of 43.68 , the sample size was estimated to be 32 per group. However, considering a possible dropout of $20 \%$, the sample size increased to 40 per group.

A total of 108 patients and their primary caregivers were consecutively assessed for eligibility, of whom 28 cases were excluded (19 lacked the inclusion criteria and 9 were dissatisfied with participation in the study). Those with inclusion criteria were non-randomly allocated to the control $(n=40)$ and experimental $(n=40)$ groups. No one lost the follow-up during the study (Figure 1).

\section{Instruments}

The data were collected by a demographic information form and Zarit Burden Interview (ZBI). The demographic questionnaire included items on the caregiver's age, sex, marital status, occupation, and education, as well as the patient's HF class, and the duration of HF. The ZBI (Cre- 
spo et al. 2005) consists of 22 items that are answered on a 5-point Likert scale from 0 (never) to 4 (always). Accordingly, the total scores can range between 0 and 88 . Scores 0-20 indicate no burden, whereas scores 21-40, 41-60, and 61-88 are regarded as moderate, moderate to the severe, and severe burden, respectively. The validity and reliability of the Persian version of the ZBI have already been assessed in earlier studies and the scale's test-retest reliability coefficient and Cronbach's alpha were reported as 0.85 and 0.88 , respectively (Mollaei et al. 2019). Pahlavanzadeh also assessed the reliability of this scale with a test-retest reliability coefficient of 0.94 (Pahlavanzadeh, Navidian, \& Yazdani 2010). The Cronbach's alpha was calculated to be 0.78 in the current study.

\section{Intervention}

Before the intervention, all the participants completed the demographic questionnaire and ZBI. The training program was then developed and implemented based on the FCEM steps, including perceived threats, selfefficacy promotion, self-esteem promotion, and evaluation for the intervention group. Training packages (i.e., pamphlets and training cards) were developed by the researchers using literature review and nursing and medical books, and confirmed by a group of cardiologists and nursing faculty members.

The program was implemented in four 10-person groups in four 120-minute sessions two days a week for four weeks. Each step was presented in two sessions. All the training sessions were presented by the first researcher with the support of a cardiologist and a psy-

Table 1. The outline of the program based on the Family-Centered Empowerment Model

\begin{tabular}{|c|c|c|c|c|}
\hline Steps & Objectives & Content & Method & Presenter \\
\hline $\begin{array}{l}\text { Step one (perceived } \\
\text { threat) }\end{array}$ & $\begin{array}{l}\text { - Introducing the role of caregiver in ensur- } \\
\text { ing the patientss health } \\
\text { - Improving the participants knowledge } \\
\text { and skills about the disease, strengthening } \\
\text { realistic expectations regarding the progno- } \\
\text { sis and treatment of the disease }\end{array}$ & $\begin{array}{l}\text { - The roles of caregiver and } \\
\text { family in disease control and } \\
\text { patient care } \\
\text { - Challenges of the family in } \\
\text { patient care } \\
\text { - Strategies to promote caregiver } \\
\text { support } \\
\text { - The nature of the disease }\end{array}$ & $\begin{array}{l}\text { Lecture, ques- } \\
\text { tion and an- } \\
\text { swering, group } \\
\text { discussion, } \\
\text { sharing caregiv- } \\
\text { erss experiences, } \\
\text { PowerPoint } \\
\text { presentation, } \\
\text { educational } \\
\text { booklet }\end{array}$ & $\begin{array}{l}\text { Cardiolo- } \\
\text { gist, the } \\
\text { researcher }\end{array}$ \\
\hline $\begin{array}{l}\text { Step two (promo- } \\
\text { tion of self-efficacy) }\end{array}$ & $\begin{array}{l}\text { - Improving the participants' knowledge } \\
\text { and skills about medication therapy } \\
\text { - Increasing the caregiver's readiness in } \\
\text { caring for the patient } \\
\text { - Improving caregiver's confidence and con- } \\
\text { trol over the patient care } \\
\text { - Improving the caregiver's and patient's } \\
\text { communication skills and adaptability in } \\
\text { patient care } \\
\text { - Reducing the stress and pressure caused } \\
\text { by the care provision }\end{array}$ & $\begin{array}{l}\text { - The importance and the role } \\
\text { of medications in preventing } \\
\text { disease recurrence } \\
\text { - Familiarity with medications, } \\
\text { side effects and related care } \\
\text { - Adaptation skills, stress man- } \\
\text { agement skills, effective com- } \\
\text { munication with the patient, } \\
\text { problem solving methods and } \\
\text { time management }\end{array}$ & $\begin{array}{l}\text { Lecture, ques- } \\
\text { tion and an- } \\
\text { swering, group } \\
\text { discussion, } \\
\text { sharing caregiv- } \\
\text { erss experiences, } \\
\text { educational } \\
\text { CD, telephone } \\
\text { counseling and } \\
\text { follow-up }\end{array}$ & $\begin{array}{l}\text { The re- } \\
\text { searcher, a } \\
\text { psychiatric } \\
\text { nurse }\end{array}$ \\
\hline $\begin{array}{l}\text { Step three (promo- } \\
\text { tion of self-esteem) }\end{array}$ & $\begin{array}{l}\text { - Maintaining and promoting the health of } \\
\text { the caregiver } \\
\text { - Increasing the caregiver's information } \\
\text { about the accessible support resources and } \\
\text { how to use them } \\
\text { - Increasing the caregiver's information on } \\
\text { how to care for the patient } \\
\text { - Increasing the caregiver's readiness } \\
\text { to care for the patient, improving the } \\
\text { caregiver's confidence and control over the } \\
\text { patient care situations }\end{array}$ & $\begin{array}{l}\text { - The importance of self-care } \\
\text { (adequate sleep and rest, receiv- } \\
\text { ing psychological support from } \\
\text { family and others) } \\
\text { - Introducing the available sup- } \\
\text { port resources and educational } \\
\text { services } \\
\text { - Patient care during the crisis } \\
\text { of symptoms, when and how } \\
\text { to refer the patient to medical } \\
\text { centers when a crisis occurs }\end{array}$ & $\begin{array}{l}\text { Lecture, ques- } \\
\text { tion and answer- } \\
\text { ing, telephone } \\
\text { counseling and } \\
\text { follow-up }\end{array}$ & $\begin{array}{l}\text { The re- } \\
\text { searcher }\end{array}$ \\
\hline $\begin{array}{l}\text { Step four (evalua- } \\
\text { tion) }\end{array}$ & $\begin{array}{l}\text { Determining perceived threat, self-efficacy } \\
\text { and self-esteem of the caregivers }\end{array}$ & $\begin{array}{l}\text { - Summarizing the content pre- } \\
\text { sented in previous sessions } \\
\text { - Answering to the questionnaire } \\
\text { and final evaluation }\end{array}$ & $\begin{array}{l}\text { Lecture, ques- } \\
\text { tion and answer- } \\
\text { ing, PowerPoint } \\
\text { presentation }\end{array}$ & $\begin{array}{l}\text { The re- } \\
\text { searcher }\end{array}$ \\
\hline
\end{tabular}


chiatric nurse (Table 1). At the end of each session, the topics were summarized, participants' questions were answered, and the date and purpose of the next session were announced. At the beginning of the next session, caregivers were asked questions to ensure that they understood what was presented in the previous session.

The researchers also provided participants with their phone numbers; hence, they could call and get advice if they had any questions. Also, the first researcher contacted the subjects once a week to be informed about the implementation process of the programs. Both groups received routine care (self-care, diet, medication, physical activity, and daily activities); however, at the beginning and end of the intervention, care measures, such as controlling blood pressure and blood sugar were taken to encourage them to stay in the study. Immediately after the intervention and one month later, all the subjects were invited to the health center again and completed the ZBI.

\section{Data analysis}

The data were analyzed using the SPSS software version 16. (SPSS Inc., Chicago, IL, USA). The normality of quantitative variables was examined using the Kolmogorov-Smirnov test. Descriptive statistics (frequency, percentage, mean, and standard deviation) were used to describe and classify the data. The Chi-square test was used to compare the mean of demographic and clinical variables. The t-test was used to compare the mean caregiver burden scores between the two groups before, immediately after, and one month after the intervention. Repeated measures Analysis of Variance (ANOVA) was used to compare the mean caregiver burden between the three measurement time points. The level of significance was set at $<0.05$.

\section{Results}

The Mean \pm SD age of the older adults in the intervention and the control groups was $68.02 \pm 8.62$ and $67.6 \pm 8.40$, respectively. Also, the Mean $\pm \mathrm{SD}$ age of the caregivers in the intervention and control groups was $40.8 \pm 6.55$ and $41.80 \pm 5.12$, respectively. Other demographic characteristics are shown in Tables 2 and 3. The Chi-square test showed no significant difference between the intervention and the control groups respecting participants' demographic characteristics ( $\mathrm{P}>0.05$; Tables 2 and 3 ).

There was no statistically significant difference between the groups respecting the pretest mean scores of $\mathrm{ZBI}(\mathrm{P}>0.05)$. However, the mean caregiver burden score was significantly different between the intervention and the control groups, immediately after $(\mathrm{P}<0.05)$ and one month after the intervention $(\mathrm{P}<0.05)$. The results of repeated measures ANOVA illustrated a significant differ-

Table 2. Characteristics of the older adults with heart failure in the control $(n=40)$ and intervention $(n=40)$ groups

\begin{tabular}{|c|c|c|c|c|}
\hline \multirow{2}{*}{\multicolumn{2}{|c|}{ Variables }} & \multicolumn{2}{|c|}{ No. $(\%)$ or Mean \pm SD } & \multirow{2}{*}{$\mathbf{P}^{*}$} \\
\hline & & Control Group & Intervention Group & \\
\hline \multirow{3}{*}{ Sex } & Female & $26(65)$ & $26(65)$ & \multirow{3}{*}{1} \\
\hline & & & & \\
\hline & Male & $14(35)$ & $14(35)$ & \\
\hline \multirow{3}{*}{ Education level } & Below high school diploma & $24(60)$ & $23(57.5)$ & \multirow{3}{*}{0.39} \\
\hline & & & & \\
\hline & High school diploma and over & $16(40)$ & $17(42.5)$ & \\
\hline \multirow{3}{*}{ Marital status } & Single & $9(22.5)$ & $11(27.5)$ & \multirow{3}{*}{0.78} \\
\hline & & & & \\
\hline & Married & $31(77.5)$ & $29(72.5)$ & \\
\hline \multirow{3}{*}{ Occupation } & Employed & $21(52.5)$ & $22(55)$ & \multirow{3}{*}{0.96} \\
\hline & & & & \\
\hline & Unemployed & 19(47.5) & $18(45)$ & \\
\hline \multirow{3}{*}{ Heart failure class } & Class II & $22(55)$ & $24(60)$ & \multirow{3}{*}{0.76} \\
\hline & & & & \\
\hline & Class III & $18(45)$ & $16(40)$ & \\
\hline & Age, year* & $67.6 \pm 8.40$ & $68.2 \pm 8.62$ & 0.80 \\
\hline \multicolumn{2}{|c|}{ Duration of heart failure, year ${ }^{* *}$} & $3.92 \pm 1.45$ & $3.90 \pm 1.33$ & 0.94 \\
\hline
\end{tabular}

${ }^{*}$ Chi-square test; ${ }^{* *}$ Independent t-test.

Client- Centered Nursing Care 
Table 3. Characteristics of the caregivers in the control $(n=40)$ and the intervention $(n=40)$ groups

\begin{tabular}{|c|c|c|c|c|}
\hline & \multirow{2}{*}{ Variables } & \multicolumn{2}{|c|}{ No. $(\%)$ or Mean \pm SD } & \multirow{2}{*}{$\mathbf{P}^{*}$} \\
\hline & & Control Group & Intervention Group & \\
\hline \multirow[b]{2}{*}{ Sex } & Female & $25(62.5)$ & $21(52.5)$ & \multirow[b]{2}{*}{1} \\
\hline & Male & $15(37.5)$ & $19(47.5)$ & \\
\hline \multirow{2}{*}{ Education level } & Less than high school diploma & $18(45)$ & $15(37.5)$ & \multirow{2}{*}{0.39} \\
\hline & High school diploma and over & $22(55)$ & $25(62.5)$ & \\
\hline \multirow[b]{2}{*}{ Marital status } & Single & $10(25)$ & $13(32.5)$ & \multirow[b]{2}{*}{0.78} \\
\hline & Married & $30(75)$ & $27(67.5)$ & \\
\hline \multirow{2}{*}{ Occupation } & Employed & $22(55)$ & $21(52.5)$ & \multirow[b]{2}{*}{0.96} \\
\hline & Unemployed & $18(45)$ & 19(47.5) & \\
\hline & Age, year ${ }^{* *}$ & $41.8 \pm 5.12$ & $40.8 \pm 6.55$ & 0.51 \\
\hline
\end{tabular}

ence between the mean ZBI scores in the three measurement time points $(\mathrm{P}<0.0001)$. In other words, over time, the mean caregiver burden scores significantly decreased in the intervention group, while it did not significantly change in the control group. The effect of the group variable was also statistically significant $(\mathrm{P}<0.05$; Table 4$)$.

\section{Discussion}

HF imposes many physical, psychological, social, and economic burdens on patients' families (Thornton et al. 2008) and caregivers of these patients perceive high levels of burden (Ponikowski et al. 2014; Savarese \& Lund 2017). Families and caregivers with less supportive resources are more likely to suffer from a high burden and stress (Carlson \& Miller 2017).

The present study showed that the implementation of FCEM reduced the caregiver burden in caregivers of older adults with HF. Some studies have examined the effect of this model on the burden perceived by the caregivers of patients with Parkinson's disease (Shoghi, Shahbazi \& Seyedfatemi 2019) and cancer (Bagheri et al. 2019) and reported that it could significantly decrease the caregiver burden. It has also been reported that training the family can improve patients' clinical status and social functioning as well as relatives' perceived burden (Magliano et al. 2006). Using the FCEM significantly increased the perceived self-efficacy in caregivers of patients undergoing heart valve replacement (Abedini, Zareiyan \& Alhani 2020). Nonetheless, Garcia et al. reported that a family-centered intervention did not significantly affect family functioning, health behaviors, medication follow-up, knowledge of the disease, and caregiver burden (García-Huidobro et al. 2011). This difference might be related to the differences in subjects, settings, cultural contexts, and training methods.

Our findings along with the aforementioned studies confirmed that implementation of FCEM is effective in

Table 4. The Mean \pm SD burden scores in the three measurement time points

\begin{tabular}{|c|c|c|c|c|c|c|c|}
\hline \multirow{3}{*}{ Variable } & \multirow{3}{*}{ Group } & \multicolumn{3}{|c|}{ Intervention } & \multirow{2}{*}{\multicolumn{3}{|c|}{$\mathbf{P}^{*}$}} \\
\hline & & Before & Immediately After & After One Month & & & \\
\hline & & \multicolumn{3}{|c|}{ Mean $\pm S D$} & Group & Time×Group & Time \\
\hline \multirow{3}{*}{$\begin{array}{l}\text { Caregiver } \\
\text { burden }\end{array}$} & Intervention & $69.93 \pm 0.40$ & $57.05 \pm 0.37$ & $44.08 \pm 0.49$ & & & \\
\hline & Control & $69.89 \pm 0.50$ & $69.90 \pm 0.38$ & $69.97 \pm 0.56$ & $<0.0001$ & $<0.0001$ & $<0.0001$ \\
\hline & $P^{*}$ & 0.93 & $<0.001$ & $<0.001$ & & & \\
\hline
\end{tabular}

${ }^{\star}$ Repeated measure analysis; ${ }^{*}$ Independent t-test.

Client- Centered Nursing Care 


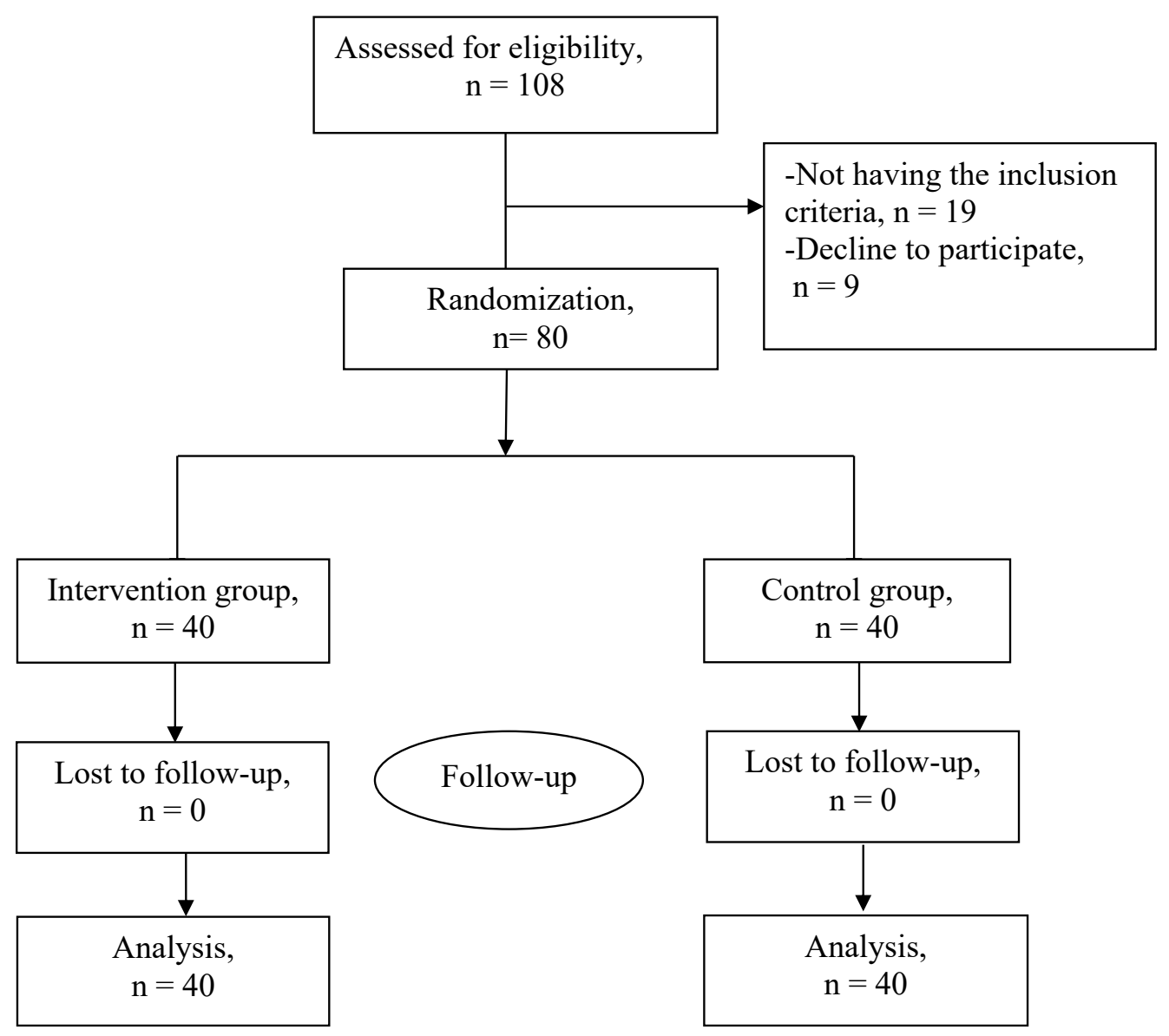

Figure 1. The study flow diagram

Client- Centered Nursing Care

decreasing the burden perceived by the family caregivers of older adults with HF. Tan (2006) also emphasized that accompanying a family member with the patient in educational classes not only improves the quality of care but also increases the effectiveness of training in preventing complications of the disease and reduces the burden on the caregiver (Tan 2006). In this regard, caregivers' satisfaction will increase and their perceived caring burden will decrease (Abedini, Zareiyan \& Alhani 2020; Magliano et al. 2006). Using the empowerment model focusing on the management of care programs leads to reduced burden of care and improving the role of caregivers. Therefore, considering the effectiveness of this intervention and the persistence of its effect over time, it is recommended to implement FCEM programs for caregivers of patients with HF.

\section{Conclusion}

The results of the study showed that the implementation of the FCEM reduces the burden of care in caregivers of older adults with HF. Therefore, special attention should be paid to empowering the families of these patients. Due to the ease and low cost of this program and the high prevalence of $\mathrm{HF}$, nurses and other health care providers are recommended to train and empower family members of patients with HF using FCEM. It is recommended that similar studies be performed on caregivers of patients with other heart diseases and heart problems using random group assignments. It should be noted that differences in the level of learning of family caregivers as well as the difficulty of transmitting what they have learned to elderly patients in the family have been beyond the control of the researchers.

\section{Ethical Considerations}

\section{Compliance with ethical guidelines}

The permission to conduct the study was obtained from the Ethics Committee (Code: IR.KAUMS.NUHEPM. REC.1398.065) and Vice Chancellor for Research of Kashan University of Medical Sciences. All the study participants signed written informed consent, and all their rights were observed according to the latest version of the 
Helsinki Declaration. The subjects were assured that participating in the study would not cost them anything. They can withdraw from the study at any time. Their participation or withdrawal would not affect their treatment process.

\section{Funding}

This study was supported by the Research Deputy of Kashan University of Medical Sciences, Kashan, Iran (Grant number: 98170).

\section{Authors' contributions}

Conceptualization: Ismail Azizi-Fini and Sedighe Jafari-Diziche; Design: Ismail Azizi-Fini and FatemeSadat Izadi-Avanji; Definition of intellectual content: Ismail Azizi-Fini, Seyed Majid Derakhshandeh and Fateme-Sadat Izadi-Avanji; literature search: Ismail Azizi-Fini and Sedighe Jafari-Diziche; Data acquisition: Sedighe Jafari-Diziche, Seyed Majid; Data analysis: Fateme Atoof; Manuscript preparation: Ismail AziziFini and Sedighe Jafari-Diziche; Manuscript editing and manuscript review: Ismail Azizi-Fini, Seyed Majid Derakhshandeh, and Fateme-Sadat Izadi-Avanji.

\section{Conflict of interest}

The authors declared no conflict of interest.

\section{Acknowledgments}

The authors would like to thank the Research Administration of Kashan University of Medical Sciences, Kashan.

\section{References}

Abedini, F., Zareiyan, A. \& Alhani, F., 2020. The effects of the familycentered empowerment model on self-efficacy and self-esteem among the family caregivers of patients with prosthetic heart valve: A controlled clinical trial. Nursing and Midwifery Studies, 9(2), pp. 61-7. [DOI:10.4103/nms.nms_45_18]

Bagheri, S., et al. 2019. Effect of implementing family-centered empowerment model on burden of care in caregivers of the elderly with Parkinson's disease. Evidence Based Care Journal, 9(3), pp. 41-8. [DOI:10.22038/EBC].2019.14043]

Bamari, F., Madarshahian, F. \& Barzgar, B., 2016. [Reviews burden of caring caregivers of patients with type ii diabetes referred to diabetes clinic in the city of Zabol (Persian)]. Journal of Diabetes Nursing, 4(2), pp. 59-67. http://jdn.zbmu.ac.ir/article-1-209-en.html

Carlson, J. M. \& Miller, P. A., 2017. Family burden, child disability, and the adjustment of mothers caring for children with epilepsy:
Role of social support and coping. Epilepsy \& Behavior, 68, pp. 16873. [DOI:10.1016/j.yebeh.2017.01.013] [PMID]

Casimir, Y. E., et al. 2013. Effectiveness of patient-centered self-care education for adults with heart failure on knowledge, self-care behaviors, quality of life, and readmissions: A systematic review protocol. JBI Evidence Synthesis, 11(8), pp. 107-28. [DOI:10.11124/ jbisrir-2013-920]

Chong, W. F., Ding, Y. \& Heng, B. H., 2011. A comparison of comorbidities obtained from hospital administrative data and medical charts in older patients with pneumonia. BMC Health Services Research, 11(1), pp. 1-9. [DOI:10.1186/1472-6963-11105] [PMID] [PMCID]

Crespo, L., María, López, J. \& Zarit, S. H., 2005. Depression and anxiety in primary caregives: A comparative study of caregivers of demented and nondemented older persons. International Journal of Geriatric Psychiatry, 20(6), pp. 591-2. [DOI:10.1002/ gps.1321] [PMID]

Dharmarajan, K., et al. 2013. Diagnoses and timing of 30-day readmissions after hospitalization for heart failure, acute myocardial infarction, or pneumonia. JAMA, 309(4), pp. 355-63 [DOI:10.1001/jama.2012.216476] [PMID] [PMCID]

García-Huidobro, D., et al. 2011. Family intervention to control type 2 diabetes: A controlled clinical trial. Family Practice, 28(1), pp. 4-11. [DOI:10.1093/fampra/cmq069] [PMID]

Heidari, M, et al. 2007. [The effect of empowerment model on quality of life of Diabetic adolescents (Persian)]. Iranian Journal of Pediatrics, 17(1), pp. 87-94. https://www.sid.ir/en/Journal/ViewPaper.aspx?ID=78709

Kato, N., et al. 2009. Adherence to self-care behavior and factors related to this behavior among patients with heart failure in Japan. Heart E Lung, 38(5), pp. 398-409. [DOI:10.1016/j. hrtlng.2008.11.002] [PMID]

Magliano, L., et al. 2006. Family psychoeducational interventions for schizophrenia in routine settings: Impact on patients' clinical status and social functioning and on relatives' burden and resources. Epidemiology and Psychiatric Sciences, 15(3), pp. 219-27. [DOI:10.1017/S1121189X00004474] [PMID]

Milbury, K., et al. 2013. Longitudinal associations between caregiver burden and patient and spouse distress in couples coping with lung cancer. Supportive Care in Cancer, 21(9), pp. 2371-9. [DOI:10.1007/s00520-013-1795-6] [PMID] [PMCID]

Moattari, M., et al. 2012. The effect of empowerment on the self-efficacy, quality of life and clinical and laboratory indicators of patients treated with hemodialysis: A randomized controlled trial. Health and Quality of Life Outcomes, 10, p. 115 [DOI:10.1186/1477-7525-10-115] [PMID] [PMCID]

Mollaei, F., et al. 2019. [Correlation between spiritual well-being and burden of care in family caregivers of cancer patients (Persian)]. Journal of Hayat, 24(4), pp. 296-309. http:// hayat. tums.ac.ir/article-1-2583-en.html

Nomali, M., et al. 2017. [Effect of self-monitoring program on outcomes of heart failure: Review of literature (Persian)]. Iranian Journal of Cardiovascular Nursing, 6(1), pp. 62-75. http:/ / journal.icns.org.ir/article-1-482-en.html

Pahlavanzadeh, S., Navidian, A. \& Yazdani, M., 2010. [The effect of psycho-education on depression, anxiety and stress in family caregivers of patients with mental disorders (Persian)]. Journal of Kermanshah University of Medical Science, 14(3), p. e79476. https:// sites.kowsarpub.com/jkums/articles/79476.html 
Ponikowski, P., et al. 2014. Heart failure: Preventing disease and death worldwide. ESC Heart Failure, 1(1), pp. 4-25. [DOI:10.1002/ehf2.12005] [PMID]

Rahimi Kordshooli, K. Rakhshan, M. \& Ghanbari, A., 2018. The effect of family-centered empowerment model on the illness perception in heart failure patients: A randomized controlled clinical trial. Journal of Caring Sciences, 7(4), pp. 189-95. [DOI:10.15171/jcs.2018.029] [PMID] [PMCID]

Rezai Asl, H., et al. 2017. [The effectiveness of "Family-Centered Empowerment Model" on the treatment adherence of patients with type II diabetes and heart disorder admitted to AJA Hospitals, during year 2015 (Persian)]. Journal of Military Caring Sciences, 4(1), pp. 58-69. [DOI:10.29252/mcs.4.1.58]

Salehi, S., Mehralin, H. \& Hasheminia, A. M., 2016. [Effect of family empowerment model on re-hospitalization and outpatient visits in a period of nine months among heart failure patients (Persian)]. Knowledge and Health, 11(3), pp. 1-7. [DOI:10.22100/ jkh.v11i3.1258]

Sanaie, N., et al. 2014. [The effects of family-based empowerment on family cooperation in following patient treatment regime after coroner arteries bypass surgery (Persian)]. Modern Care Journal, 11(1), pp. 19-27. http://sid.bums.ac.ir/dspace/ handle/bums/5065

Savarese, G. \& Lund, L. H., 2017. Global public health burden of heart failure. Cardiac Failure Review, 3(1), pp. 7-11. [DOI:10.15420/cfr.2016:25:2]

Shoghi, M. Shahbazi, B. \& Seyedfatemi, N., 2019. The effect of the Family-Centered Empowerment Model (FCEM) on the care burden of the parents of children diagnosed with cancer. Asian Pacific Journal of Cancer Prevention, 20(6), pp. 1757-64. [DOI:10.31557/APJCP.2019.20.6.1757] [PMID] [PMCID]

Tan, H., 2006. Examining the influence of family support on diabetes education behavioural outcomes [MSc. thesis]. St. Catharines: Brock University. http://hdl.handle.net/10464/2796

Thornton, N., et al. 2008. Family function in cognitively normal children with epilepsy: Impact on cometence and problem behaviors. Epilepsy \& Behavior, 12(1), pp. 90-5. [DOI:10.1016/j. yebeh.2007.07.008] [PMID]

Utne, I., et al. 2013. Association between hope and burden reported by family caregivers of patients with advanced cancer. Supportive Care in Cancer, 21(9), pp. 2527-35. [DOI:10.1007/ s00520-013-1824-5] [PMID]

Vahidi, M., et al. 2016. Other side of breast cancer: Factors associated with caregiver burden. Asian Nursing Research, 10(3), pp. 201-6. [DOI:10.1016/j.anr.2016.06.002] [PMID] 
This Page Intentionally Left Blank 